\title{
Drivers of landholder participation in tender programs for Australian biodiversity conservation
}

Louise Blackmore ${ }^{\mathrm{a}}$ and Graeme J. Doole ${ }^{\mathrm{a}, \mathrm{b}}$

${ }^{a}$ Centre for Environmental Economics and Policy, School of Agricultural and Resource Economics, Faculty of Natural and Agricultural Sciences, University of Western Australia, 35 Stirling Highway, Crawley, Western Australia 6009, Australia.

b Department of Economics, Waikato Management School, University of Waikato, Private Bag 3105, Hamilton, New Zealand.

\section{Keywords}

Market-based instrument; Australia; biodiversity conservation; conservation tender; landholder participation; maximum entropy.

\section{Correspondence}

Louise Blackmore, Centre for Environmental Economics and Policy, School of Agricultural and Resource Economics, University of Western Australia, 6009, Western Australia, Australia. Tel: +61 086488 5505. E-mail: louise.blackmore@uwa.edu.au

\begin{abstract}
Conservation tender programs have been widely applied to biodiversity conservation in Australia and internationally in recent decades. Increasing participation rates is critical to these schemes, as competition is required for the cost-effectiveness benefits of the tender system to be fully realised. However, knowledge relating to the drivers of landholder participation in tender programs is limited. This study aims to identify the relative importance of different drivers of participation in Victorian conservation tenders. The novel method of maximum entropy ordinal regression is used given the small sample size, and supplemented with qualitative data obtained through face-to-face interviews. The regression analysis reveals that strong relationships between agencies and landholders and a low administrative burden drive increased participation. The provision of education, support, and easilyintegrated management practices, however, may drive lower participation, with landholders
\end{abstract}


confident to undertake conservation activities independently of assistance. Some evidence emerges that ten-year contracts may be well-received. A key concern is low additionality in biodiversity benefits, with typical tender participants displaying a strong conservation ethic and high levels of management activity pre-participation. This work has shown that in conservation policies involving self-selection by participants, economic incentives for adoption may be less important than non-monetary drivers.

\section{Introduction}

Conservation on public land alone is increasingly acknowledged as being inadequate to slow the rapid biodiversity loss occurring globally (Mora and Sale, 2011). Hence, many nations are looking towards conservation on private land as an additional solution. Conservation tender (CT) programs have been widely implemented in recent decades on an international level. The United States Conservation Reserve Program has operated since 1985, and uses a competitive tendering process to allocate funding to private landholders for cropland retirement (Ribaudo et al., 2001). From 1991-2005, the English Countryside Stewardship Scheme in Britain selected successful landholder bids based on value-for-money (Morris, 2004). In Germany, tenders have been trialled by conservation agencies in lower Saxony and North Rhine Westphalia targeting cropland retirement and grassland management respectively (Latacz-Lohmann and Schilizzi, 2005).

In Australia, the first BushTender trial commenced in Victoria in 2001 (Stoneham et al., 2003), and tender initiatives have since been implemented in Western Australia (Gole et al., 2005), South Australia (e.g. Connor et al., 2008), Tasmania (MJA, 2010b), and Queensland (e.g. Windle and Rolfe, 2008). Many of these initiatives were driven by the National MarketBased Instrument Pilot Program (NMBIPP) from 2002-2008 (BDA Group, 2009). The largescale Environmental Stewardship Program (ESP) has also implemented conservation tenders spanning multiple Australian states in recent years (MJA, 2010a).

CT programs require landholders to competitively bid for conservation funds by nominating the compensation they require to adopt specified conservation management activities. Theoretically, this ability to extract the opportunity cost of alternative management practices for individual landholders allows tenders to achieve regional biodiversity management goals on private land at lower cost than other policy options like flat-rate grants (Latacz-Lohmann 
and Schilizzi, 2005). However, successful tender programs must attract enough landholder participants to generate competition and minimise the potential for strategic bidding behaviour (Ferraro, 2008). The CT mechanism ensures that each landholder's bidmaximising incentive is tempered by a counteracting motivation towards bidding lower to remain competitive. With too few participants, this counteracting incentive effect diminishes and the likelihood of collusion and strategic behaviour increases (Latacz-Lohmann and Schilizzi, 2005). The encouragement of landholder participation in CT programs is therefore vitally important if tender systems are to achieve cost-effective conservation outcomes.

The primary objective of this analysis is to identify the relative importance of different factors that motivate landholders to participate in CT programs for biodiversity conservation. An analysis of what drives participation is important to inform the process of tender design and thus improve the future implementation of such programs. This work has broad international relevance, given the widespread global application of tender programs for biodiversity conservation. The broad implementation of CT throughout Australia provides a number of valuable case studies.

Drivers of participation in Australian CT programs have received previous research attention. Following the BushTender trial, the Victorian Department of Sustainability and Environment collated the results of market research surveys that obtained feedback from both participant and non-participant landholders regarding the tender approach (DSE, 2006). Whitten et al. (2007) drew upon experience with competitive tender programs in Queensland, Victoria and New South Wales to propose a framework for identifying potential impediments to participation. Relevant research has also been conducted in Queensland, where the motivations and barriers to landholder participation in three different biodiversity conservation programs have been assessed (Moon and Cocklin, 2011; Moon et al., 2012). One component of a large-scale investigation of multiple Australian incentive programs assessed the influence of various landholder characteristics on participation (Morrison et al., 2008). Zammit (2013) reported on the social benefits of landholder engagement in tender programs within the Tasmanian Forest Conservation Fund (MJA, 2010b) and ESP (MJA, 2010a). This analysis differs from these studies for two reasons. First, it is the first to use maximum entropy ordinal regression techniques to assess the relative importance of multiple drivers of participation in CT programs specifically. Thus, it differs from the application of 
Morrison et al. (2008) in which binary logistic regression is used. Second, it is the first study to include program design and context features rather than landholder characteristics alone.

\section{Methods and Data}

\subsection{Case study background}

Survey participants had been involved in BushTender, EcoTender or Green Graze programs for biodiversity conservation in Victoria. The first BushTender in 2001 consisted of two trials: one in Gippsland and the other in North Central Victoria (DSE, 2006). The program targeted biodiversity conservation outcomes, offering three-year contracts to landholders based on management inputs. Successful bids were selected using a Biodiversity Benefits Index, that evaluated value-for-money in terms of a Biodiversity Significance Score and a Habitat Services Score (Stoneham et al., 2003). Variations of BushTender have since emerged throughout Victoria. For example, EcoTender extends the BushTender model to consider environmental outcomes beyond biodiversity conservation (Eigenraam et al., 2007). Green Graze was a pilot project implemented in the Goulburn Broken and North Central catchments of Victoria, which sought to promote improved vegetation cover on livestock farms (Moll et al., 2007).

\subsection{Methods overview}

The research was conducted as follows:

1. Unstructured interviews were carried out with experienced practitioners to identify potential key drivers of landholder participation in CT.

2. Extensive literature review was undertaken to generate further information and deeper understanding of identified drivers.

3. The information gained in Steps 1 and 2 was used to formulate a structured quantitative/qualitative survey instrument investigating the drivers of higher probabilities of participation in future CT programs.

4. The structured survey was iteratively refined based on peer review by researchers within various government and regional catchment management institutions.

5. The structured survey was personally implemented through face-to-face methods.

6. Descriptive statistics were computed for all quantitative data. 
7. Generalised maximum entropy regression analysis was conducted to quantitatively investigate drivers of higher probabilities of participation in future CT programs.

8. Qualitative data was coded into themes to support the quantitative results.

9. Results from the descriptive statistics and regression analyses were matched with qualitative data to deepen understanding of the quantitative results.

\subsection{Survey design and implementation}

The unstructured interviews of experienced practitioners (Step 1 in Section 2.2) consisted of a very broad discussion of the general strengths and weaknesses of Australian CT, and key areas of potential improvement. Furthermore, these discussions provided input into the literature review with interviewees asked to suggest useful references relevant to the research question.

The combined quantitative/qualitative structured survey for landholders (Step 5 in Section 2.2) investigated the following broad topics as related to participation in CT:

1. Transaction costs (e.g. paperwork, time)

2. Financial benefits (e.g. short-term financial gain)

3. Non-financial benefits (e.g. lifestyle benefits)

4. Environmental outcomes (e.g. enhanced diversity in birds/plants)

5. Interactions with the implementing agency (e.g. education, monitoring, relationships)

6. Contract length preferences

7. Areas for improvement in the performance of the implementing agency

The quantitative component elicited responses on a 0-7 Likert agreement scale $(0=$ don't know, 1 = strongly disagree, 2 = disagree, 3 = somewhat disagree, $4=$ neither agree nor disagree, 5 = somewhat agree, $6=$ agree, $7=$ strongly agree). The dependent variable for the regression analysis was defined using this Likert scale, and indicated the extent to which participants agreed that they were likely to participate in a future conservation tender program. The qualitative element utilised open-format questions. Demographic information was also collected. The interviewer verbally delivered all questions and noted responses. A copy of the survey is available from the primary author upon request. 
Face-to-face interviews were conducted in October 2012 with 23 landholders located in the North Central, Wimmera and Mallee catchments of Victoria, including 17 successful participants (obtained funding) and 6 unsuccessful participants (submitted a bid but did not obtain funding) in the BushTender (Stoneham et al., 2003), EcoTender (Eigenraam et al., 2007) or Green Graze (Moll et al., 2007) programs. Participation was defined as having submitted a bid to the implementing agency. Access to respondents was obtained through snowball sampling, whereby personal networks were used to identify suitable participants dynamically during the structured survey period (Bryman, 2012). The sample included both commercial and non-commercial landholders, identified as such by directly asking landholders to specify the primary use of their property. Interviews generally occurred in the home of the respondent. This encouraged landholder commitment, especially given the complexity of the survey instrument.

Respondents were assigned a numerical and a non-numerical identifier. The numerical identifiers reflect the order in which participants were interviewed. BT indicates participation in BushTender, ET in EcoTender and GG in Green Graze. The lower-case letter affixed to each of the BT, ET or GG identifiers denotes whether the landholder was successful (s) or unsuccessful (u) in obtaining a conservation contract in the particular program.

\subsection{Data}

Some survey data was analysed without regression (unstructured data) and other data was analysed with regression (regression data). This distinction was determined by the nature of the data and its relevance to the question analysed in the regression analysis (see below). The descriptive statistics obtained for the unstructured data are presented in Table 1, and discussed in Section 3. The results of the regression analysis are presented in Table 2, and are discussed in Section 4.

\section{[Insert Table 1 and 2 near here]}

Dummy variables were constructed for the respondent gender (GEND), farm type (TYPE), and respondent education (EDUC) variables (Table 2). Respondent age (AGE) was a categorical variable taking seven levels $(1=0-20$ years, $2=21-30$ years, $3=31-40$ years, 4 $=41-50$ years, $5=51-60$ years, $6=61-70$ years, $7=71+$ years $)$. The proxy measure for 
productive capacity $(P R O D)$ was a continuous numerical variable constructed by combining farm size and rainfall data into a single index. This proxy measure was computed through: PROD $=$ farm size $*$ rainfall $* 0.0001$. All other variables were ordinal categorical variables based upon the Likert agreement scale outlined above. Missing data were estimated using cubic hermite interpolation (Massopust, 2009).

\subsection{Generalised maximum entropy methods}

Regression analysis was used to analyse the capacity of a set of regressors from survey data to describe the likelihood of each respondent participating in a future conservation tender scheme. The dependent variable was an ordinal variable defined over 8 levels (Section 2.3). A general multiple regression problem was defined:

$$
y_{t}=\sum_{k=1}^{K} \beta_{k} X_{k, t}+e_{t} .
$$

where $y_{t}$ is a dependent variable, $\beta_{k}$ are unknown parameters for $k=1,2, \ldots, K$ to be estimated, $X_{k, t}$ are a set of measured attributes for each parameter $k=1,2, \ldots, K$ over $t=1,2, \ldots, N$ observations, and $e_{t}$ are a series of unobserved random errors.

The statistical analysis of non-experimental data to study socio-economic phenomena is common, with the discipline of econometrics focused on this practice (Greene, 2012). Ordinary least squares (OLS) is the standard method used to determine the unknown $\beta_{k}$ in eq. 1 when the dependent variable $y$ takes continuous values. OLS involves the identification of the regression coefficients that minimise the sum of the squared errors $\left(e_{t}\right)$ across the $N$ data points. In contrast, if dependent variable $y$ takes discrete (integer) values only, then maximum likelihood (ML) methods, such as logit or probit models, are used that specify cumulative distribution functions linking outcome probabilities and the explanatory variables (Mittelhammer et al., 2000).

Though widely used, these methods require that sample data be particularly well-behaved to provide accurate insight. Four key conditions are required: 
1. OLS and ML methods require that there are more data points than explanatory variables for estimation to occur.

2. Large sample sizes are required within both OLS and ML to increase their ability to estimate the true values of coefficients (Greene, 2012; Greenland, 2000).

3. OLS and ML both require that explanatory variables are not strongly correlated with one another; otherwise, estimates will be unstable and have high variance.

4. Inference from OLS and ML models is misguided if the data does not match the distributional assumptions made by the practitioner.

Generalised maximum entropy (GME) methods provide an alternative means to estimate regression models, with either continuous or discrete dependent variables (Golan et al., 1996). Several primary benefits are noteworthy. First, GME models can be applied where there are more, the same, or less explanatory variables than there are data points, as the measure of entropy (see below) provides a consistent and conservative means to assess the relative information associated with alternative solutions. Second, the use of the entropy measure to assess relative information content is also not sensitive to correlations between explanatory variables. Third, GME requires no specific distributional assumptions to be made; rather, the distribution of errors and coefficients is estimated from the data. Last, GME models provide straightforward means to include prior information.

The GME method requires that coefficient and error terms are redefined as discrete probability distributions. These distributions consist of a set of probabilities, each defined for a fixed value (support) defined as a possible outcome for that coefficient or error term. For example, a coefficient could consist of the weighted average of 2 supports $\{-5,5\}$ through the equation $\beta=-5 P_{1}+5 P_{2}$, where the probabilities are defined $\left\{P_{1}, P_{2}\right\}$. The probabilities for the coefficient and error terms are determined through nonlinear optimisation. The optimisation problem involves identifying the sets of probabilities for the coefficient and error terms that maximise an information measure called Shannon's entropy (Jaynes, 2003). (See Section 2.6 for a more formal specification of this procedure.) Maximisation of entropy subject to no data constraints yields a uniform distribution, which represents a state of true uncertainty. However, the addition of informative data points as constraints in the optimisation problem will cause these distributions to move towards more meaningful specifications. 
This approach is based on the maximum entropy principle, which describes that probabilities associated with different outcomes should be assigned such that the least informative distribution that satisfies the data set is generated (Golan et al., 1996). This conservative approach is based on the principle of indifference, which states that the least informative distributions should be selected if there is insufficient information to provide further distinction between data points (Jaynes, 2003).

GME methods have been proven through extensive simulation experiments to provide improved performance, relative to traditional estimation techniques such as OLS and ML, when data is ill-posed (e.g. Golan et al., 1996; Golan et al., 1997). Accordingly, these methods have now been broadly applied particularly in agricultural economics (e.g. Akdeniz et al., 2011; Heckelei and Wolff, 2003; Lence and Miller, 1998; Léony et al., 1999; Paris and Howitt, 1998).

Data from 23 landholders was analysed here using an entropy estimator. This sample size is low relative to many econometric studies, particularly those involving discrete dependent variables. ML methods introduce substantial bias in the analysis of small samples, complicating the identification of the true coefficient values (Greenland, 2000). These problems are promoted in ordinal regression studies, as rare events complicate the identification of general relationships (King and Zeng, 2001). As an information-based measure, GME methods identify the coefficient values that could have generated the data in the most number of ways. Thus, even if there is a low amount of information available, GME will utilise this but not extrapolate past that which is available (Golan et al., 1996). The capacity for the GME estimator to provide robust prediction of the dependent variable in such cases was evident here, given that an excellent fit of $R^{2}=0.85$ was obtained (Section 4.1).

\subsection{Generalised maximum entropy model}

This section summarises how GME methods can be used to estimate a model with ordered discrete dependent variables (Golan et al., 1997). The following subsections describe the technique; more detail is available in Golan et al. (1996) and Golan et al. (1997).

In the GME method, coefficients $\left(\beta_{k}\right)$ and errors $\left(e_{t}\right)$ are not single values, as in OLS. Rather, they are redefined as the expected value of a discrete, finite probability distribution. 
The values (supports) that an explanatory variable $\beta_{k}$ can take within this distribution are defined over an interval $\left[z_{k, 1}, z_{k, C}\right]$, where $z_{k, 1}<z_{k, 2}<\ldots<z_{k, C}$ and $c=[1,2, \ldots, C]$ is an index. The values (supports) that an error term $e_{t}$ can take within this distribution are defined over an interval $\left[v_{t, 1}, v_{t, D}\right]$, where $v_{t, 1}<v_{t, 2}<\ldots<v_{t, D}$ and $d=[1,2, \ldots, D]$ is an index.

The probability distribution for coefficient $\beta_{k}$ is estimated through:

$$
\beta_{k}=\sum_{c=1}^{C} P_{k, c} Z_{k, c}
$$

where probabilities $P_{k, c}$ are decision variables.

The probability distribution for the error term $e_{t}$ is estimated through:

$$
e_{t}=\sum_{d=1}^{D} W_{t, d} v_{t, d}
$$

where probabilities $W_{t, d}$ are decision variables. Probabilities are subject to the standard normalisation constraints: $P_{k, c} \in[0,1], \sum_{c=1}^{C} P_{k, c}=1, W_{t, d} \in[0,1]$, and $\sum_{d=1}^{D} W_{t, d}=1$.

The probabilities $P_{k, c}$ and $W_{t, d}$ are selected through nonlinear optimisation to maximise the entropy criterion:

$$
G=-\sum_{k=1}^{K} \sum_{c=1}^{C} P_{k, c} \ln \left(P_{k, c}+10^{-8}\right)-\sum_{t=1}^{T} \sum_{d=1}^{D} W_{t, d} \ln \left(W_{t, d}+10^{-8}\right)
$$

The $10^{-8}$ terms are incorporated, as otherwise the natural logarithm is undefined when either $P_{k, c}=0$ or $W_{t, d}=0$. Estimation of an ordinal model using GME involves disaggregating the data sample into $J$ groups. The categorical variable is defined $y_{t}=[1,2, \ldots, J]$ for $\left[y_{t}^{*} \leq \mu_{1}, \mu_{1}<y_{t}^{*} \leq \mu_{2}, \ldots, \mu_{J-1} \leq y_{t}^{*}\right]$, respectively, where $\mu_{j}$ are threshold parameters for ordered categories $j=[1,2, \ldots, J-1]$. Threshold parameters segregate sample data into $J$ 
strata, consistent with standard ordinal logit models (Greene, 2012). Let $t_{j}$ for $j=[1,2, \ldots, J]$ denote the first observation in each strata and $t^{j}$ for $j=[1,2, \ldots, J]$ denote the last observation in each strata.

The information constraints are then defined:

$$
\begin{gathered}
\sum_{c=1}^{C} P_{k, c} z_{k, c} X_{k, t}+\sum_{d=1}^{D} W_{t, d} v_{t, d}>\mu_{j-1}, \forall t \in\left[t_{j}, \ldots, t^{j}\right], J \geq j \geq 1, \text { and } \\
\sum_{c=1}^{C} P_{k, c} z_{k, c} X_{k, t}+\sum_{d=1}^{D} W_{t, d} v_{t, d} \leq \mu_{j}, \forall t \in\left[t_{j}, \ldots, t^{j}\right], J \geq j \geq 1,
\end{gathered}
$$

where $X_{k, t}$ are a set of measured attributes for each of the $K$ parameters over the $N$ observations. Note from above that $\mu_{j}$ are threshold parameters for ordered categories $j=[1,2, \ldots, J-1]$. The left hand side (LHS) of both equations is the entropy equivalent of the regression equation (defined in eq. 1), given that $\beta_{k}=\sum_{c=1}^{C} P_{k, c} z_{k, c}$ and $e_{t}=\sum_{d=1}^{D} W_{t, d} v_{t, d}$. Accordingly, eq. 5 defines the lower bound for each stratum through the requirement that the estimated regression line (the LHS of eq. 5) must be greater than a lower bound (threshold $\left.\mu_{j-1}\right)$. Likewise, eq. 6 defines the upper bound for each stratum through the requirement that the estimated regression line (the LHS of eq. 6) must be less than or equal to an upper bound (threshold $\mu_{j}$ ). The optimisation problem involved in GME estimation is to maximise eq. 4 subject to eqs. 5-6 and the normalisation constraints. Following optimisation, estimated coefficients are computed using eq. 2 , while the error terms are computed using eq. 3.

\subsection{Inference and diagnostics in the GME model}

The information index $I_{k}$ is a value between 0 and 1 that denotes the amount of information in a given coefficient. $I_{k}=0$ denotes full uncertainty regarding the true value, while $I_{k}=1$ denotes perfect certainty regarding the true value. The index is computed through: 


$$
I_{k}=1-\frac{\sum_{c=1}^{C} P_{k, c} \ln \left(P_{k, c}\right)}{\ln (C)} .
$$

The entropy-ratio statistic $\left(E_{k}\right)$ for testing the null hypothesis $H_{0}: \beta_{k}=0$ is:

$$
E_{k}=2\left[G_{0}-G_{U}\right] \text {, }
$$

where $G_{0}$ is the maximum entropy value obtained with the constraint $\beta_{k}=0$ and $G_{U}$ is the maximum entropy value obtained when no parameters are constrained. The statistic $E_{k}$ has a $\chi_{1}^{2}$ distribution in the limit when $H_{0}$ is true.

The entropy-ratio statistic for the regression ( $E R$ ) for testing the null hypothesis $H_{0}: \beta_{k}=0$ $\forall k$ is:

$$
E R=2\left[G_{0}-G_{U}\right],
$$

where $G_{0}$ is the maximum entropy value obtained with the constraint $\beta_{k}=0 \forall k$ and $G_{U}$ is the maximum entropy value obtained when no parameters are constrained. The statistic $E R$ has a $\chi_{K-1}^{2}$ distribution in the limit when $H_{0}$ is true.

Impact indicators $\left(P_{k}\right)$ denote the impact of an explanatory variable $X_{k}$ on a dependent variable accounting for the magnitude of estimated slope coefficients and the sample variance of the explanatory variable (covariate) of interest (Ghadim et al., 2005).

This procedure augments the standard approach (Ghadim et al., 2005) through normalising the value of the impact indicator according to the information content $\left(I_{k}\right)$ of the estimated coefficient. A higher value of an impact indicator $\left(P_{k}\right)$ denotes that an explanatory variable $X_{k}$ has a greater effect on the dependent variable. For example, impact indicators of $P_{A 1}=0.25$ and $P_{A 2}=0.5$ indicate that covariate $A 2$ has twice as large an impact on the dependent variable, relative to covariate A1, following normalisation. 
An impact indicator for each coefficient $\beta_{k}$ is computed through:

$$
P_{k}=I_{k}\left|\left(Y_{k}^{U}-Y_{k}^{L}\right)\right|
$$

where $Y_{k}^{L}$ and $Y_{k}^{U}$ are the levels of the dependent variable (computed from the estimated regression line) when $X_{k}$ is set one standard deviation below and above its mean, respectively, and data $X_{l}$ for $l \neq k$ are set at their means. Each impact indicator is defined as an absolute value, so that consistent with previous studies (e.g. Ghadim et al., 2005), the higher an impact indicator for a given variable is in magnitude, the more important this covariate is in explaining the dependent variable.

\subsection{Application of the entropy model to the sample data}

The entropy model described in Section 2.6 was estimated using nonlinear programming in the CONOPT3 solver in GAMS (Brooke et al., 2012). 50 supports for the estimated coefficients were defined in the interval $[-0.5,0.5]$. 50 supports for the error terms were defined in the interval $[-0.15,0.15]$. Supports were selected using the general approach of Golan et al. (1996). First, each set of supports is defined equidistant on each side of zero. Second, support bounds are equal for all coefficients and for all error terms. Third, the number of supports is high to increase model precision. Last, bounds are estimated by selecting those that maximise the information content of the regression, as determined by normalised entropy. This decreases the chance that narrower support bounds inflate precision risk (Golan et al., 1996). Nevertheless, sensitivity analysis shows that the relative magnitude of coefficients and impact indicators is not affected by broader bound definition or increases in the number of support bounds used.

\section{Analysis of unstructured data}

\subsection{Investment of time in conservation activity before and after the program}

Landholders only mildly agreed that the time they spent on conservation had increased during $(T I D U$, mean $=4.61)$ and after their participation in the CT program (Table 1). Mean values reflect the average response recorded on the seven point Likert scale described in Section 2.3. 
Most respondents were conservation-minded, with $83 \%$ of the sample stating they were active members of at least two environmental groups. This is consistent with the findings of DSE (2006) and Moon et al. (2012), suggesting that tender schemes may be failing to generate biodiversity benefits greatly in excess of those which would have been attained in any case. Efforts to engage landholders outside existing conservation communities may improve the additionality of outcomes achieved in CT programs. Motivation crowding effects may ultimately ensue where previously voluntary conservation effort becomes financially compensated, resulting in a net decrease in voluntary effort. Given the small sample examined here, there is limited evidence to support this hypothesis. However, the investigation of motivation crowding effects resulting from CT program implementation is an important area for further research.

\subsection{Contract length preferences}

Figure 1 presents the willingness of respondents to participate in contracts of specified durations in the future. Landholders were most willing to accept five-year (PAR5, mean = $5.30)$ and ten-year contracts $(P A R 10$, mean $=5.35)$ (Figure 1 , Table 1$)$, even though $50 \%$ of the respondents involved in five-year programs disagreed that this time-frame was sufficient to achieve meaningful biodiversity outcomes. Respondents felt that ten-year contracts would increase their chances of achieving lasting biodiversity outcomes, irrespective of climatic fluctuations and without limiting future management options or the resale value of their property. Results show a reduced willingness to accept contracts longer than ten years (Figure 1, Table 1), with few landholders feeling that they were able to make such long-term commitments due to factors such as retirement or reluctance to constrain future management by others.

[Insert Figure 1 near here]

\subsection{Suggestions for improvement in the performance of the implementing agency}

Figure 2 displays the extent to which respondents felt particular aspects of the implementing agency could be improved to encourage greater participation rates in future tender programs. Mean scores close to the neutral point for introductory materials (IAINT, mean $=4.35$ ), management actions $(I A M G T$, mean $=4.91)$, and payment schedule $(I A P A Y$, mean $=4.09)$ indicate that these were not seen as requiring significant improvement (Figure 2, Table 1). 
By contrast, landholders generally felt that the provision of information workshops, the program entry process, and bid selection required improvement, with mean scores of 5.17 (IAINF), 5.22 (IAENT) and 5.30 (IASEL), respectively (Figure 2, Table 1). Tender programs typically limit the quantity of information provided to participants to minimise the possibility of collusion, which involves landholders conspiring to submit inflated bids (Latacz-Lohmann and Schilizzi, 2005). In this study, being unable to communicate with other participants, having limited support in constructing bids, and being confused about the bid-selection process left many landholders feeling isolated, frustrated, and even betrayed by the agency. There is evidence that landholder participants in the ESP have experienced similar issues (MJA, 2010a; Zammit, 2013). Our results support those of Whitten et al. (2007) and Moon et al. (2012), indicating a need to ensure that landholders receive assistance and support, while seeking to minimise collusion among them.

[Insert Figure 2 near here]

Monitoring is of fundamental importance to achieving conservation benefits in tender programs, and yet was most strongly perceived as requiring improvement (IAMON, mean = 5.39) (Figure 2, Table 1). Most landholders submitted annual reports to the agency and monitoring site visits were generally infrequent or non-existent. A lack of monitoring visits made most landholders feel isolated and unsure of their ability to complete contracted tasks. Low monitoring activity by agency employees reflects transactions costs concerns and a wish to promote ownership of the scheme by landholders. However, our results support those of Morrison et al. (2008), suggesting that more active, frequent monitoring by agencies could enhance participation rates in CT programs. 


\section{Drivers of landholder participation in the regression analysis}

Section 4.1 discusses the fit of the regression model. The remaining sections present the 7 most-highly ranked regressors in terms of their impact on the dependent variable, as measured through the impact indicator (Section 2.5).

\subsection{Model fit}

The model has a good fit to the survey data. The $R^{2}$ value indicates the strength of the association between the observed dependent variable and the predicted dependent variable. This is computed as $R^{2}=0.85$, which is deemed excellent considering the limited sample size $(n=23)$ and the cross-sectional nature of the data set. The entropy ratio of the regression (eq. 9) tests the hypothesis that all coefficient values are simultaneously equal to zero. The computed value of $E R=31.11$ is above the critical value for a chi-square distribution at $24-1=23$ degrees of freedom at a $0.001 \%$ level of significance $\left(\chi_{23,0.001}^{2}=7.529\right)$. This allows us to reject the null hypothesis that all estimated coefficients are simultaneously equal to zero. Moreover, 15 of the 24 explanatory variables are statistically significant. This result may be surprising given that the problem has more explanatory variables than data points, but is typical of the ability of entropy methods to provide insight in the presence of ill-posed data (Paris and Howitt, 1998).

\subsection{Relationships with staff from the implementing agency (RELA)}

The presence of strong relationships with agency staff (RELA) is identified as the predictor variable most strongly driving likely landholder participation in a future tender program (Table 2, 3). Landholders who experience a better rapport with conservation agencies are more likely to participate in future CT. This is consistent with the above discussion that respondents generally believe that better relationships with agency staff could overcome limitations currently perceived with the provision of information workshops, the program entry process, and bid selection (Section 3.3). Zammit (2013) drew attention to the significance of personal engagement with landholder participants in the Tasmanian Forest Conservation Fund, while Moon et al. (2012) emphasised the importance of two-way communication between landholders and government in driving participation. Accordingly, 
investing in more positive and stable relationships with landholders is a key strategy for increasing participation in future tender programs.

[Insert Table 3 near here]

\subsection{Low up-front administration costs (COPW)}

Low up-front costs relating to additional administration (COPW) had the second-highest impact on future participation in a tender program (Table 2, 3). Landholders who found the paperwork associated with the tender program to be relatively easy and straightforward tended to be more positively-disposed towards future participation. Discussion during the interviews reinforced this:

I didn't find the entry paperwork or the annual reports to be too bad. [LH19 BTs]

Several landholders found the paperwork associated with tender programs to have been very arduous and complicated, and a strong deterrent to future participation:

The level of paperwork I had to wade through was overwhelming and highly frustrating, and in the end that's why I quit the scheme. [LH1 BTs]

Around $60 \%$ of our respondents agreed to some extent that the costs of completing the paperwork associated with the CT (which included the opportunity cost of their time) were low. Moon et al. (2012) obtained similar results in Queensland, finding that the majority of participants in conservation programs did not find the associated paperwork to be particularly time-consuming, although there were some exceptions. By contrast, participants in various conservation programs investigated by Morrison et al. (2008) indicated that the time required to complete paperwork was excessive. These findings indicate that efforts to streamline the process of entering CT programs and simplify the reporting process may promote higher participation rates.

\subsection{Support and education from the implementing agency (SUPP)}

Support and education by the agency (SUPP) was the third-strongest driver of likely future participation in a tender program (Table 2, 3). Landholders that perceived themselves as 
having been well-supported and well-educated were less likely to participate in a future CT. This contradicts previous research, which indicates that support and education drives higher rates of participation (Whitten et al., 2007). Section 3.2 highlights that $83 \%$ of respondents are active members of at least two environmental groups and that generally respondents did not alter their conservation management efforts significantly during or after the CT program. Moreover, $40 \%$ of the sample found the cost of additional administrative work prohibitive. Accordingly, good support and education by the implementing agency may have been felt by participants to adequately equip them with the necessary skills to undertake future conservation projects, independent of agency involvement and the administrative burden associated with participation. This was captured well by the comments of one respondent:

One of the major problems with these schemes is that people can't be bothered wading through all the paperwork, so ultimately they end up going solo and just doing what they want to do independently of government, CMAs or environmental groups. [LH14 BTs]

\subsection{Social standing amongst neighbouring landholders (STAN)}

Enhancement of social standing amongst neighbouring landholders (STAN) was the fourth most powerful driver of future participation in tender programs (Table 2, 3). Some landholders described meeting with jealousy and opposition from their communities due to their participation in a CT:

I definitely wouldn't say [participation] enhanced my standing. [LH22 BTs]

However, rather than deterring them from participation in conservation initiatives, such sentiments seemed to evoke defiance and determination:

I don't care what they think because I don't do it for them. [LH8 ETs]

Throughout the interviews, it generally appeared that the more opposition a landholder faced, the more willing they were to participate in future programs. 


\subsection{Good fit with existing land management or farming practices (GFIT)}

Fit with existing land management or farming practices (GFIT) was the fifth-strongest driver of future participation (Table 2, 3). Landholders who felt that the tender program integrated easily with their existing land management or farming system were less likely to participate in a future CT. This result is converse to the proposal of Pannell et al. (2006) that farmers will adopt innovations that fit easily within their farming systems. However, it is intuitive given the specific context of tender programs. Section 4.5 indicates that landholders may become confident to manage an area for biodiversity conservation independently of agency involvement after their contracts expire. This action also lowers administration costs.

\subsection{Benefit to others more than self (BEOT)}

The perception that tender programs were of greater benefit to others (BEOT) had the sixthhighest impact indicator (Table 2, 3). When discussing the distribution of benefits of their participation in the CT, many landholders expressed a view that they had not entered the program with an expectation of generating immediate benefits to themselves, so much as for future generations or the community at large. This altruistic attitude is also very apparent in the qualitative results, with many landholders expressing a desire to bequeath healthier land to future generations.

\subsection{Significant increase to short-term farm income (STIN)}

Significant increases to short-term income (STIN) had the seventh-highest impact indicator (Table 2, 3). Survey results indicate that 75 per cent of respondents would participate in future programs, but only 25 per cent of respondents believe that conservation tenders increase short-term income. Accordingly, the regression reports a negative association between these two variables. This can be interpreted as reinforcing the importance of nonmonetary concerns in driving future participation in tender programs.

\section{Conclusions}

The primary objective of this analysis was to identify the relative importance of different factors that motivate landholders to participate in tender programs for biodiversity conservation. 
Results from the analysis of unstructured data yield some important insights:

- Landholders are likely to be receptive to ten-year contracts, finding that shorter contracts (e.g. five years or less) often fail to achieve desired outcomes, whereas longer contracts (e.g. 15 years or more) represent a commitment beyond what they are willing to accept. This suggests a tension between landholders' desire to implement long-term conservation management strategies, and concerns relating to retirement, mortality, property sale values and options available to future generations.

- Landholders feel that agency performance has been adequate in the areas of providing introductory materials and advertising, specifying management actions and payment scheduling. These may thus be considered low-priority targets for future improvements.

- Landholders feel agency performance needs improvement in the areas of providing information workshops, providing support during bid construction and bid selection, and monitoring. These areas thus constitute high priority targets in future CT programs, though potential collusion remains a problem.

Additionally, the regression analysis has identified several key factors:

- Landholders are likely to participate in future CT programs when they have a strong, respectful, and continuous relationship with the implementing agency involving faceto-face contact. CT programs are thus more likely to succeed in areas characterised by strong agency-landholder relationships. This is also thought to apply to the adoption of innovations more broadly (Pannell et al., 2006). Where such relationships are absent, personal engagement with landholders should be a high priority to ensure program success.

- Landholders are more likely to participate in future CT programs when the administrative load associated with participation is low. Streamlining the participation process is thus likely to enhance participation in future programs.

- Landholders with an altruistic attitude and strong conservation focus, with a relatively low focus on monetary outcomes, are more likely to participate in future CT programs. Investigating strategies to engage landholders without these attributes will 
be critical to the achievement of broad-scale biodiversity outcomes. Accordingly, this has been a focus of the recent ESP (MJA, 2010a).

- Landholders may be less likely to participate in future CT programs when they have the necessary skills to undertake conservation works independently and/or the conservation options fit well with their current system. Further research is needed to ensure that this relationship is consistently observed. If this is the case, ensuring that landholders leave programs with a high skill level and a realistic management plan will liberate funding to recruit new landholders into future CT schemes.

Consideration of these factors is likely to drive higher participation rates in conservation tender programs. This work has shown that in conservation policies involving self-selection by participants, economic incentives for adoption may be of lesser importance than nonmonetary drivers. However, practical application of these results should take into account the limitations of this study. The sample size used is small, and the means by which respondents were accessed allowed considerable scope for self-selection by participants. Consequently, further research is needed to ensure that the key insights of this paper apply more broadly across the agricultural sector... 


\section{Acknowledgments}

This research was conducted with the support of funding from the Australian Government's National Environmental Research Program.

\section{References}

Akdeniz, F., Cabuk, A., Guler, H., 2011. Generalised maximum entropy estimators: applications to the Portland Cement dataset. Open Statistics and Probability Journal 3, 13-20.

BDA Group, 2009. Final Report of the National Market Based Instruments Pilot Program. BDA Group, Manuka, Australian Capital Territory.

Brooke, A., Kendrick, D., Meeraus, A., Raman, R., 2012. GAMS - A user's guide. GAMS Development Corporation, Washington D.C.

Bryman, A., 2012. Social Research Methods, 4 ed. Oxford University Press, Oxford.

Clayton, H., 2011. The Crowding-Out of Public Good Conservation Effort: An Application to Market-based Biodiversity Conservation Policy in Australia, Agricultural and Resource Economics. University of Western Australia, Perth, Western Australia.

Connor, J.D., Ward, J.R., Bryan, B., 2008. Exploring the cost effectiveness of land conservation auctions and payment policies. Australian Journal of Agricultural and Resource Economics 52, 303-319.

DSE, 2006. BushTender - the landholder perspective. Department of Sustainability and Environment, Victoria.

Eigenraam, M., Strappazzon, L., Lansdell, N., Beverly, C., Stoneham, G., 2007. Designing frameworks to deliver unknown information to support market-based instruments. Agricultural Economics 37, 261-269.

Ferraro, P.J., 2008. Asymmetric information and contract design for payments for environmental services. Ecological Economics 65, 810-821.

Ghadim, A.K.A., Pannell, D.J., Burton, M.P., 2005. Risk, uncertainty, and learning in adoption of a crop innovation. Agricultural Economics 33, 1-9.

Golan, A., Judge, G., Miller, D., 1996. Maximum Entropy Econometrics. Wiley, New York.

Golan, A., Judge, G., Perloff, J., 1997. Estimation and inference with censored and ordered multinomial response data. Journal of Econometrics 79, 23-51.

Gole, C., Burton, M., Williams, K., Clayton, H., Faith, D.P., White, B., Huggett, A., Margules, C., 2005. Auction for Landscape Recovery: Project Final Report. WWF Australia. 
Greene, W., 2012. Econometric Analysis. Prentice Hall, Boston.

Greenland, S., 2000. Small-sample bias and corrections for conditional maximum-likelihood odds-ratio estimators. Biostatistics 1, 113-122.

Heckelei, T., Wolff, H., 2003. Estimation of constrained optimisation models for agricultural supply analysis based on generalised maximum entropy. European Review of Agricultural Economics 30, 27-50.

Jaynes, E., 2003. Probability Theory. Cambridge University Press, Cambridge.

King, G., Zeng, L., 2001. Logistic Regression in Rare Events Data. Political Analysis 9, 137163.

Latacz-Lohmann, U., Schilizzi, S., 2005. Auctions for Conservation Contracts: A Review of the Theoretical and Empirical Literature. Scottish Executive Environment and Rural Affairs Department.

Lence, S., Miller, D., 1998. Estimation of multi-output production functions with incomplete data: A generalised maximum entropy approach. European Review of Agricultural Economics 25, 188-209.

Léony, Y., Peeters, L., Quinqu, M., Surry, Y., 1999. The Use of Maximum Entropy to Estimate Input-Output Coefficients From Regional Farm Accounting Data. Journal of Agricultural Economics 50, 425-439.

Massopust, P., 2009. Interpolation and approximation with splines and fractals. Oxford University Press, Oxford, UK.

Mittelhammer, R., Judge, G., Miller, D., 2000. Econometric Foundations. Cambridge University Press, Cambridge.

MJA, 2010a. Review of the Environmental Stewardship Program: A report prepared for the Department of Sustainability, Environment, Water, Population and Communities. Marsden Jacob Associates.

MJA, 2010b. The Tasmanian Forest Conservation Fund and associated programs: purpose, performance and lessons. Marsden Jacob Associates., Tasmania.

Moll, J., Miles, C., Dorrough, J., Crosthwaite, J., 2007. Green Graze Pilot Project Final Report. Goulburn-Broken Catchment Management Authority.

Moon, K., Cocklin, C., 2011. Participation in biodiversity conservation: Motivations and barriers of Australian landholders. Journal of Rural Studies 27, 331-342.

Moon, K., Marshall, N., Cocklin, C., 2012. Personal circumstances and social characteristics as determinants of landholder participation in biodiversity conservation programs. Journal of Environmental Management 113, 292-300. 
Mora, C., Sale, P., 2011. Ongoing global biodiversity loss and the need to move beyond protected areas: a review of the technical and practical shortcomings of protected areas on land and sea. Marine Ecology Progress Series 434, 251-266.

Morris, C., 2004. Networks of agri-environmental policy implementation: a case study of England's Countryside Stewardship Scheme. Land Use Policy 21, 177-191.

Morrison, M., Durante, J., Greig, J., Ward, J., 2008. Encouraging Participation in Market Based Instruments and Incentive Programs. Land and Water Australia.

Pannell, D.J., Marshall, G.R., Barr, N., Curtis, A., Vanclay, F., Wilkinson, R., 2006. Understanding and promoting adoption of conservation practices by rural landholders. Australian Journal of Experimental Agriculture 46, 1407-1424.

Paris, Q., Howitt, R.E., 1998. An Analysis of Ill-Posed Production Problems Using Maximum Entropy. American Journal of Agricultural Economics 80, 124-138.

Ribaudo, M.O., Hoag, D.L., Smith, M.E., Heimlich, R., 2001. Environmental indices and the politics of the Conservation Reserve Program. Ecological Indicators 1, 11-20.

Stoneham, G., Chaudhri, V., Ha, A., Strappazzon, L., 2003. Auctions for conservation contracts: an empirical examination of Victoria's BushTender trial. Australian Journal of Agricultural and Resource Economics 47, 477-500.

Whitten, S., Reeson, A., Windle, J., Rolfe, J., 2007. Barriers to and Opportunities for Increasing Participation in Conservation Auctions. CSIRO Sustainable Ecosystems.

Windle, J., Rolfe, J., 2008. Exploring the efficiencies of using competitive tenders over fixed price grants to protect biodiversity in Australian rangelands. Land Use Policy 25, 388-398.

Zammit, C., 2013. Landowners and conservation markets: Social benefits from two Australian government programs. Land Use Policy 31, 11-16. 
Table 1: Descriptive statistics for the unstructured (non-regression) data. The first row contains the descriptive statistics for the dependent variable in the regression analysis (DEPV), describing the likelihood of future CT participation.

\begin{tabular}{|c|c|c|c|c|c|}
\hline $\begin{array}{l}\text { Variable } \\
\text { name }\end{array}$ & Description & Mean & $\begin{array}{l}\text { Std. } \\
\text { dev. }\end{array}$ & Min. & Max. \\
\hline$D E P V$ & $\begin{array}{l}\text { Dependent variable. Likely to participate in } \\
\text { future CT programs for biodiversity } \\
\text { conservation. }\end{array}$ & 5.35 & 1.7 & 2 & 7 \\
\hline DUR1 & $\begin{array}{l}\text { CT improved biodiversity on tender site } \\
\text { during contract term }\end{array}$ & 5.00 & 1.57 & 2 & 7 \\
\hline AFT1 & $\begin{array}{l}\text { CT improved biodiversity on tender site after } \\
\text { contract expired }\end{array}$ & 5.52 & 1.38 & 2 & 7 \\
\hline DUR2 & $\begin{array}{l}\text { CT improved biodiversity elsewhere on } \\
\text { property during contract term }\end{array}$ & 4.26 & 1.66 & 1 & 7 \\
\hline AFT2 & $\begin{array}{l}\text { CT improved biodiversity elsewhere on } \\
\text { property after contract expired }\end{array}$ & 4.78 & 1.51 & 2 & 7 \\
\hline$T I D U$ & $\begin{array}{l}\text { CT increased time spent on biodiversity } \\
\text { conservation during contract term }\end{array}$ & 4.61 & 1.90 & 2 & 7 \\
\hline TIAF & $\begin{array}{l}\text { CT increased time spent on biodiversity } \\
\text { conservation after contract expired }\end{array}$ & 4.87 & 1.69 & 1 & 7 \\
\hline BEFA & $\begin{array}{l}\text { CT encouraged use of conservation practices } \\
\text { on whole property }\end{array}$ & 4.74 & 1.71 & 1 & 7 \\
\hline COOP & $\begin{array}{l}\text { CT encouraged cooperation with } \\
\text { neighbouring landholders }\end{array}$ & 3.70 & 1.82 & 1 & 6 \\
\hline OTHR & $\begin{array}{l}\text { CT encouraged achievement of other (non- } \\
\text { biodiversity) environmental benefits }\end{array}$ & 4.61 & 1.83 & 1 & 7 \\
\hline PAR5 & $\begin{array}{l}\text { Willingness to participate in 5-year CT } \\
\text { contract }\end{array}$ & 5.30 & 1.46 & 2 & 7 \\
\hline PAR10 & $\begin{array}{l}\text { Willingness to participate in } 10 \text {-year CT } \\
\text { contract }\end{array}$ & 5.35 & 1.61 & 2 & 7 \\
\hline PAR15 & $\begin{array}{l}\text { Willingness to participate in 15-year CT } \\
\text { contract }\end{array}$ & 4.43 & 2.00 & 2 & 7 \\
\hline PAR20 & $\begin{array}{l}\text { Willingness to participate in 20-year CT } \\
\text { contract }\end{array}$ & 4.13 & 1.98 & 2 & 7 \\
\hline PARPE & $\begin{array}{l}\text { Willingness to participate in perpetual CT } \\
\text { contract }\end{array}$ & 4.35 & 2.21 & 1 & 7 \\
\hline IAINT & $\begin{array}{l}\text { Agency needs to improve CT introductory } \\
\text { materials }\end{array}$ & 4.35 & 1.87 & 1 & 7 \\
\hline IAINF & $\begin{array}{l}\text { Agency needs to improve CT information } \\
\text { workshops }\end{array}$ & 5.17 & 1.53 & 1 & 7 \\
\hline IAENT & Agency needs to improve CT entry process & 5.22 & 1.09 & 4 & 7 \\
\hline IASEL & $\begin{array}{l}\text { Agency needs to improve CT bid-selection } \\
\text { process }\end{array}$ & 5.30 & 1.11 & 4 & 7 \\
\hline IAMGT & $\begin{array}{l}\text { Agency needs to improve allowable CT } \\
\text { management actions }\end{array}$ & 4.91 & 1.41 & 2 & 7 \\
\hline IAMON & $\begin{array}{l}\text { Agency needs to improve CT monitoring } \\
\text { schedule }\end{array}$ & 5.39 & 0.99 & 4 & 7 \\
\hline IAPAY & $\begin{array}{l}\text { Agency needs to improve CT payment } \\
\text { schedule }\end{array}$ & 4.09 & 1.53 & 1 & 7 \\
\hline
\end{tabular}


Table 2: Results of the entropy regression. A higher value of an impact indicator shows that the corresponding covariate is a more important descriptor of the dependent variable, while the sign of the estimated coefficient indicates the direction of the relationship.

\begin{tabular}{|c|c|c|c|c|c|}
\hline Variable & Description & $\begin{array}{l}\text { Estimate } \\
\left(\beta_{k}\right)^{a}\end{array}$ & $\begin{array}{l}\text { Info. } \\
\text { index } \\
\left(I_{k}\right)\end{array}$ & $\begin{array}{l}\text { Entropy ratio } \\
\left(E_{k}\right)\end{array}$ & $\begin{array}{l}\text { Impact } \\
\text { indic. } \\
\left(P_{k}\right)\end{array}$ \\
\hline INT & Intercept. & -0.21 & 0.07 & 0.68 & 0.01 \\
\hline$A G E$ & Age of respondent. & $0.29 * * *$ & 0.14 & 12.52 & 0.09 \\
\hline GEND & Respondent is female. & $0.46^{* * *}$ & 0.56 & 71.47 & 0.22 \\
\hline TYPE & Farm is non-commercial. & 0.09 & 0.01 & 0.15 & 0.00 \\
\hline EDUC & $\begin{array}{l}\text { Respondent is university } \\
\text { educated. }\end{array}$ & 0.16 & 0.04 & 1.19 & 0.01 \\
\hline PROD & $\begin{array}{l}\text { Proxy measure for farm } \\
\text { productivity. }\end{array}$ & 0.03 & 0.00 & 0.06 & 0.00 \\
\hline FUND & $\begin{array}{l}\text { CT funding was sufficient to } \\
\text { cover participation costs. }\end{array}$ & $0.11^{* *}$ & 0.02 & 3.93 & 0.01 \\
\hline STIN & $\begin{array}{l}\text { CT significantly increased } \\
\text { short-term income. }\end{array}$ & $-0.35 * * *$ & 0.24 & 197.68 & 0.26 \\
\hline LTIN & $\begin{array}{l}\text { CT significantly increased } \\
\text { long-term income. }\end{array}$ & -0.06 & 0.01 & 0.51 & 0.00 \\
\hline RISK & CT reduced financial risk. & $0.36^{* * *}$ & 0.24 & 19.10 & 0.25 \\
\hline$C O P W$ & $\begin{array}{l}\text { CT provide low additional } \\
\text { administration. }\end{array}$ & $0.39 * * *$ & 0.31 & 15.63 & 0.53 \\
\hline COMG & $\begin{array}{l}\text { CT has low ongoing } \\
\text { management costs. }\end{array}$ & -0.11 & 0.02 & 1.98 & 0.01 \\
\hline FAIR & $\begin{array}{l}\text { Use of CT is fairer than flat } \\
\text { payments. }\end{array}$ & $0.28 * * *$ & 0.14 & 53.49 & 0.14 \\
\hline FLEX & $\begin{array}{l}\text { Use of CT is more flexible } \\
\text { than flat rate grants. }\end{array}$ & $0.23^{* * *}$ & 0.09 & 25.15 & 0.08 \\
\hline GFIT & $\begin{array}{l}\text { CT fit in well with current } \\
\text { farming system. }\end{array}$ & $-0.40 * * *$ & 0.34 & 21.22 & 0.28 \\
\hline EALE & CT are easy to learn about. & 0.01 & 0.00 & 0.03 & 0.00 \\
\hline MANA & CT are easy to manage. & $0.22 * * *$ & 0.08 & 13.09 & 0.06 \\
\hline STAN & $\begin{array}{l}\text { Participation in CT enhances } \\
\text { standing. }\end{array}$ & $-0.37 * * *$ & 0.27 & 18.92 & 0.34 \\
\hline LIFE & $\begin{array}{l}\text { Participation in CT enhances } \\
\text { lifestyle. }\end{array}$ & 0.02 & 0.00 & 0.04 & 0.00 \\
\hline BEOT & $\begin{array}{l}\text { Participation in CT benefits } \\
\text { others more than yourself. }\end{array}$ & $0.34^{* * *}$ & 0.22 & 43.50 & 0.27 \\
\hline SUPP & $\begin{array}{l}\text { Participation in CT is aided by } \\
\text { support and education. }\end{array}$ & $-0.38 * * *$ & 0.29 & 34.93 & 0.45 \\
\hline RELA & $\begin{array}{l}\text { Participation in CT is aided } \\
\text { through strong relationships. }\end{array}$ & $0.42 * * *$ & 0.38 & 56.44 & 0.59 \\
\hline MONI & $\begin{array}{l}\mathrm{CT} \text { are effective due to } \\
\text { adequate monitoring. }\end{array}$ & $-0.17 * * *$ & 0.05 & 17.96 & 0.03 \\
\hline LENG & $\begin{array}{l}\text { CT contract was long enough } \\
\text { to achieve meaningful } \\
\text { conservation. }\end{array}$ & 0.068 & 0.007 & 1.16 & 0.002 \\
\hline
\end{tabular}

\footnotetext{
${ }^{a}$ Superscripts denote statistical significance at the $1 \%\left({ }^{* * *}\right), 5 \%\left({ }^{* *}\right)$, or the $10 \%\left({ }^{*}\right)$ level.
} 
Table 3: Explanatory variables that have the greatest impact on future participation. A higher value of an impact indicator $\left(P_{k}\right)$ shows that the corresponding covariate is a more important descriptor of the dependent variable. The "Effect" column indicates the direction of the relationship between the covariate and the dependent variable.

\begin{tabular}{|c|c|c|c|c|}
\hline Rank & $\begin{array}{l}\text { Impact } \\
\text { indic. } \\
\left(P_{k}\right)\end{array}$ & Effect & $\begin{array}{l}\text { Variable } \\
\text { name }\end{array}$ & Description \\
\hline 1 & 0.59 & + & RELA & $\begin{array}{l}\text { Aided by strong relationships with the } \\
\text { agency. }\end{array}$ \\
\hline 2 & 0.53 & + & COPW & Low ongoing administration costs. \\
\hline 3 & 0.45 & - & SUPP & $\begin{array}{l}\text { Aided by education and support from } \\
\text { agency. }\end{array}$ \\
\hline 4 & 0.34 & - & STAN & Participation in CT enhances standing. \\
\hline 5 & 0.28 & - & GFIT & Fit with current farming system. \\
\hline 6 & 0.27 & + & BEOT & $\begin{array}{l}\text { Participation in CT benefits others more } \\
\text { than yourself }\end{array}$ \\
\hline 7 & 0.26 & - & STIN & Significantly increases short term income. \\
\hline
\end{tabular}

Figure 1: Landholder preferences for CT contract duration.

(4 = neither agree nor disagree, 5 = somewhat agree, 6 = agree).

Figure 2: Areas for Improvement in the Implementing Agency. Each score identifies the extent to which the respondent believes the agency needs to improve.

(4 = neither agree nor disagree, 5 = somewhat agree, 6 = agree). 